\title{
A Longitudinal Study of Serotonergic Function in Depression
}

\author{
Robert N. Golden, M.D., Amy Durr Heine, R.N., M.S.N., R. David Ekstrom, M.A., M.P.H., \\ Joseph M. Bebchuk, M.D., F.R.C.P.C., Martha E. Leatherman, M.D., and James C. Garbutt, M.D.
}

Several reports have described abnormal neuroendocrine responses to serotonergic challenge tests in depression, but few have studied depressed patients followed longitudinally. In order to determine whether blunted prolactin responses to clomipramine challenge is a "state" vs. "trait" marker in depression, we applied this challenge paradigm to 20 patients with Major Depression prior to treatment and at three additional time points following response to desipramine: at the completion of acute treatment; at the end of the continuation phase of treatment; and after a minimum of three weeks "washout" following the discontinuation of treatment. The prolactin response to clomipramine challenge was blunted in depressed patients compared with matched healthy control subjects, at each time point over the longitudinal course of their illness and recovery. Challenge test results in depressed patients did not change after response to acute desipramine therapy, at the conclusion of the continuation phase of treatment, or while in a medication-free state of remission. Blunted prolactin response to clomipramine challenge persists in depressed patients after recovery from acute illness, and may reflect an underlying biological vulnerability.

[Neuropsychopharmacology 26:653-659, 2002] (C) 2002 American College of Neuropsychopharmacology. Published by Elsevier Science Inc.
KEY WORDS: Serotonin; Depression; Clomipramine; Desipramine; Challenge test; Prolactin

Several lines of evidence support the hypothesis that dysregulation in central serotonergic systems plays a role in the pathogenesis of major depression (Maes and Meltzer 1995). Studies have reported abnormalities in various indirect indices of central serotonergic function in depressed patients, including post-mortem brain con-

From the Department of Psychiatry, University of North Carolina School of Medicine, Chapel Hill, North Carolina (RNG, ADH, RDE, JMB, MEL, JCG), and the Clinical Research Unit, Dorothea Dix Hospital, Raleigh, North Carolina (JCG).

Address correspondence to: Robert N. Golden, M.D., Professor and Chair, Department of Psychiatry, University of North Carolina School of Medicine, Campus Box \# 7160, Chapel Hill, NC 27599 7160, Tel.: (919) 966-4738, fax: (919) 966-7659, E-mail: rgolden@ css.unc.edu

Received May 9, 2001; revised September 20, 2001; accepted October 29, 2001.

Online publication: $11 / 2 / 01$ at www.acnp.org/citations/ Npp110201198. centrations of serotonin (5-HT), its metabolites, and receptors; platelet 5-HT receptors; cerebrospinal fluid concentrations of 5-hydroxyindoleacetic acid; and neuroendocrine responses to 5-HT challenge tests (Maes and Meltzer 1995). The induction of clinical relapse in following acute tryptophan depletion in remitted depressed patients who had received treatment with serotonin selective reuptake inhibitors (SSRIs) (Delgado et al. 1990) suggests that 5-HT may also be involved in the mechanism of action of at least some successful antidepressant treatments, and that the correction of an underlying 5-HT dysfunction is linked to the initiation and maintenance of clinical remission.

While there is a substantial body of data linking perturbations in these measures of 5-HT function to depression, it remains unclear whether such findings reflect state characteristics of depressive illness, vs. trait characteristics which are indicative of an ongoing, presumably genetic vulnerability. Most studies compare patients who are currently depressed to matched 
healthy control subjects who have no personal or family history of mood disorders. Differences between these groups of subjects could reflect either state or trait phenomena associated with depression. The most useful approach in distinguishing between these would involve longitudinal studies of depressed patients over the course of treatment and recovery from their illness. Several treatment studies have applied neuroendocrine challenge tests to depressed patients before and after antidepressant treatment, and to date, the results have been inconclusive. Some reports describe enhancement of the characteristically blunted prolactin response to 5 -HT challenge in depressed patients following treatment, but this finding is not consistent $\left(\mathrm{O}^{\prime}\right.$ Keane et al. 1992; Shapira et al. 1989, 1992; Leatherman et al. 1993; Kasper et al. 1990). Others have compared 5-HT neuroendocrine challenge profiles in depressed patients who are receiving antidepressant pharmacotherapy, or who are in a current state of remission, to those of healthy volunteers or untreated patients (Flory et al. 1998; Meltzer et al. 1997). For a variety of practical and pragmatic reasons, it is difficult to reexamine in a longitudinal patient cohort 5-HT indices over the course of the acute and continuation phases of their illness, including a medication-free state of remission. However, this approach offers the greatest opportunity to dissect the trait vs. state nature of 5-HT dysregulation in depression.

The clomipramine (CMI) challenge test meets the van Praag et al. (1987) criteria for a valid 5-HT probe: (1) a dose response relationship exists for the neuroendocrine response to CMI challenge (Golden et al. 1989); (2) CMI challenge does not appear to affect catecholaminergic systems (Golden et al. 1989); and (3) the neuroendocrine response to $\mathrm{CMI}$ challenge can be blocked with a 5-HT functional antagonist (Laakmann et al. 1983). Several studies have described abnormal neuroendocrine responses to CMI challenge in depressed patients, in particular, blunted prolactin responses (Golden et al. 1990a,b, 1992; Anderson et al. 1992). The blunted prolactin response to CMI challenge in depression does not appear to be attributable to lactotroph dysfunction, since depressed patients with blunted prolactin responses to CMI mount robust prolactin responses to other stimuli, i.e. TRH challenge (Anderson et al. 1992; Golden et al. 1990a,b). We applied the CMI challenge test in a longitudinal study of depressed patients, comparing them to healthy volunteers at baseline, and then following their CMI challenge test profile over the course of treatment and recovery from their acute episode of illness. We chose as our treatment agent desipramine, a secondary amine tricyclic antidepressant which is a norepinephrine reuptake inhibitor with minimal direct pharmacological effects on 5-HT neurotransmission (Hyttel 1982), in order to avoid confounding our study of 5-HT function in depression with direct 5-HT pharmacological effects from the treating agent.

\section{METHODS}

\section{Subjects}

This study was approved by the University of North Carolina School of Medicine Committee for the Protection of the Rights of Human Subjects. Oral and written informed consent was obtained from each subject before enrollment. All potential subjects received a comprehensive medical evaluation (which included a physical examination, medical history with review of systems, and clinical laboratory testing for hematologic, hepatic, and endocrine disease), and only those who were free of any medical condition that could jeopardize their safety or complicate the interpretation of the data were eligible to participate. Female subjects were given a pregnancy test immediately prior to the study to insure that those with positive results would be excluded. All subjects received modest financial compensation for their participation, as approved by our IRB.

Depressed patients were recruited from the clinical services at the Department of Psychiatry at the University of North Carolina Hospitals and Dorothea Dix Hospital and from newspaper advertisements. Diagnoses were assigned by a board certified psychiatrist (RNG), based on all available clinical data, including the information generated by a semi-structured diagnostic interview (SCID) performed by a member of the research team. All depressed patients met DSM-III-R (American Psychiatric Association 1987) criteria for Major Depression, and achieved a score of 17 or greater on the Hamilton Depression Rating Scale (HDRS) (Hamilton 1960), 21 item version, at baseline.

Healthy control subjects were recruited via printed advertisements distributed throughout the University of North of Carolina campus and placed in the local and student newspapers. All potential control subjects underwent careful medical and psychiatric screening, including the administration of a semi-structured diagnostic interview (SADS-L) (Spitzer and Endicott 1978). Only subjects with no personal history of psychiatric illness and a negative family history for mood and anxiety disorders and alcoholism were eligible. Control subjects were free of exposure to psychoactive medications and alcohol for a minimum of three weeks prior to study.

\section{Procedures}

All depressed patients and healthy control subjects underwent standardized CMI challenge testing, as previously described (Golden et al. 1989), at baseline. Subjects were placed on a standard low monoamine, 
caffeine-controlled diet (Muscettola et al. 1977) for three days prior to each study. All subjects maintained a fasting state (except for water) beginning at midnight the night before the procedure and continuing until after the last blood specimen had been obtained. Subjects were awakened at 7:00 A.M. on the day of the infusion and were allowed to get out of bed at that time for a brief period to micturate if necessary. After that, each subject remained at strict bed rest until the procedure was completed. A research nurse ensured that subjects did not fall asleep during the procedure.

An intravenous line was started at 8:30 A.M. in an antecubital vein and kept patent with a slow drip of normal saline solution. Blood samples were obtained 30, 45 , and $60 \mathrm{~min}$ after iv insertion, and the last of these samples was used for determination of baseline prolactin concentrations. Immediately after the collection of the last pre-infusion sample, $100 \mathrm{cc}$ of normal saline containing $12.5 \mathrm{mg} \mathrm{CMI} \mathrm{(Anafranil}{ }^{\circledR}$ ) were infused over a $15 \mathrm{~min}$ period. Additional blood samples were obtained 30, 45, 60, 90, 120, and 150 min after the start of the infusion. Blood samples were drawn into disposable polypropylene syringes and transferred to heparinized polypropylene tubes. The samples were immediately placed on ice, promptly centrifuged at $4^{\circ} \mathrm{C}$, and the resultant plasma stored at $-70^{\circ} \mathrm{C}$. Plasma prolactin concentrations were measured using double antibody radioimmunoassay (RIA), which utilized commercial reagents (Bectin-Dickinson, Orangeburg NY). The sensitivity of the prolactin assay was $1.0 \mathrm{ng} / \mathrm{ml}$; the intraassay and interassay coefficients of variation were $5 \%$ and 9\%. Plasma CMI and desmethyl-CMI concentrations were measured using high performance liquid chromatography with ultraviolet detection, utilizing a modification of a previously described technique (Sutfin et al. 1984).

After completion of baseline testing, the 28 depressed patients began treatment with desipramine (DMI). Treatment was started at $75 \mathrm{mg} /$ day and titrated upward as tolerated and clinically indicated. The mean ( \pm SD) final dose was $169.1 \pm 30.0 \mathrm{mg} /$ day, and the range was 100-200 mg. "Responders" were defined a priori as those patients who achieved a reduction in their HDRS of at least $50 \%$ and whose post-treatment HDRS score was 13 or less. The 20 patients who met these criteria continued in this study and were followed longitudinally. They underwent repeat CMI testing at three additional timepoints beyond the initial baseline (Step 1) testing: at the completion of acute phase pharmacotherapy (Step 2), which followed an average of $53 \pm 15$ days on DMI; at the end of the continuation phase of treatment (Step 3), which followed $256 \pm 48$ days on DMI; and following discontinuation of pharmacotherapy and a minimum of three weeks washout from treatment (Step 4), i.e. while in a medication-free, state of remission. The mean HDRS score for the de- pressed patients at baseline (Step 1) was $21.6 \pm 4.4$ (range: 17-35); at steps 2, 3, and 4, the mean HDRS scores were $5.8 \pm 3.5,4.1 \pm 3.4$, and $3.9 \pm 3.0$, respectively.

Each depressed patient was "matched" with a healthy control subject based on age and gender. Not all of the depressed patients completed testing at each of the steps, due to various reasons, including withdrawal from the research study, missed visits, and protocol violations (e.g., IV infiltration during a challenge test, dietary or medication violation; see Table 1 ). In the analyses described below, at each step, the data from each available patient subject are compared with the baseline data from the individual corresponding control subjects that had been matched, a priori and under blinded conditions, to each patient based on age and gender. In other words, if a particular patient was not available at Step 3 (e.g., due to IV infiltration), then the corresponding control subject was also dropped from the Step 3 analysA placebo infusion was not administered. This decision was based on the practical realities and ethical considerations involved in performing baseline biological assessments in depressed patients who are not receiving active treatment. Further, earlier work has shown that placebo challenge does not affect the prolactin response to CMI challenge (Gilmore et al. 1993).

\section{Statistical Analyses}

Our index of prolactin responsivity to clomipramine challenge ("peak response") was defined as the maximum post-infusion value, represented as a percentage of the pre-infusion baseline level. Because the distributions of the peak prolactin response data often retained a distinct positive skew, even after log-transformation, as well as the relatively limited sample sizes, we selected a conservative, nonparametric approach to these analyses. The paired-sample sign test was applied to evaluate the significance of within-subject change from Step 1 to each subsequent step, and the independentsample median test was utilized to compare patients to sex-matched controls at each of the four steps.

The areas under the curves (AUCs) of CMI plasma concentrations over the two-hour post-infusion sampling period, beginning $30 \mathrm{~min}$ after start of the infusion, were calculated using the trapezoidal method, then $\log$ transformed to normalize distributions. This measure was compared over steps within subjects, using paired $t$-tests. CMI AUCs were compared between the patient and healthy control group at each step, using analysis of covariance (controlling for age).

Type 1 errors were controlled at $5 \%$ for each test; all reported $p$ values are two-tailed. In order to preserve power, no adjustment was made for multiple testing, so error rates are comparisonwise. Data processing and analysis was carried out using SAS $^{\odot}$ Software, Version 6.12. 
Table 1. Subject Demographics and Prolactin Peaks (maximum \% of baseline)

\begin{tabular}{|c|c|c|c|c|c|c|c|c|}
\hline $\begin{array}{l}\text { Subject } \\
\text { Pair }\end{array}$ & Gender & $\begin{array}{l}\text { Ages of } \\
\text { Controls }\end{array}$ & $\begin{array}{l}\text { Ages of } \\
\text { Patients }\end{array}$ & $\begin{array}{l}\text { Controls: } \\
\text { PRL Peak* }\end{array}$ & $\begin{array}{c}\text { Patients } \\
\text { at Step 1: } \\
\text { PRL Peak* }\end{array}$ & $\begin{array}{c}\text { Patients } \\
\text { at Step 2: } \\
\text { PRL Peak* }\end{array}$ & $\begin{array}{c}\text { Patients } \\
\text { at Step 3: } \\
\text { PRL Peak* }\end{array}$ & $\begin{array}{c}\text { Patients } \\
\text { at Step 4: } \\
\text { PRL Peak* }\end{array}$ \\
\hline A & $\mathrm{F}$ & 23 & 23 & 316 & 221 & 180 & 143 & 129 \\
\hline B & $\mathrm{F}$ & 23 & 27 & 148 & 267 & 210 & 152 & 140 \\
\hline C & $\mathrm{F}$ & 25 & 32 & 197 & 137 & 164 & & \\
\hline $\mathrm{D}$ & $\mathrm{F}$ & 27 & 34 & 235 & 100 & 89 & 108 & 182 \\
\hline $\mathrm{E}$ & $\mathrm{F}$ & 27 & 34 & 82 & 133 & & 85 & 126 \\
\hline $\mathrm{F}$ & $\mathrm{F}$ & 28 & 38 & 186 & 217 & 200 & & 268 \\
\hline G & $\mathrm{F}$ & 29 & 38 & 97 & 153 & 125 & 107 & 135 \\
\hline $\mathrm{H}$ & $\mathrm{F}$ & 31 & 41 & 90 & 141 & 166 & 128 & 447 \\
\hline I & $\mathrm{F}$ & 34 & 44 & 1048 & 450 & 103 & & \\
\hline $\mathrm{J}$ & $\mathrm{F}$ & 35 & 46 & 219 & 106 & 93 & & \\
\hline K & $\mathrm{F}$ & 36 & 46 & 146 & 127 & 129 & 157 & 85 \\
\hline $\mathrm{L}$ & $\mathrm{F}$ & 38 & 47 & 490 & 145 & 85 & 157 & 167 \\
\hline M & $\mathrm{F}$ & 40 & 47 & 537 & 119 & 96 & 134 & 159 \\
\hline $\mathrm{N}$ & $\mathrm{F}$ & 50 & 55 & 303 & 86 & & & 103 \\
\hline $\mathrm{O}$ & M & 30 & $20^{+}$ & 158 & 184 & 162 & & \\
\hline $\mathrm{P}$ & M & 32 & 31 & 215 & 510 & 65 & & \\
\hline $\mathrm{Q}$ & $\mathrm{M}$ & 32 & 39 & 270 & 88 & 107 & 90 & 102 \\
\hline$\hat{\mathrm{R}}$ & M & 33 & 44 & 188 & 3725 & & & 148 \\
\hline$S$ & M & 35 & 45 & 760 & 131 & 140 & 100 & 127 \\
\hline $\mathrm{T}$ & $\mathrm{M}$ & 39 & 49 & 232 & 117 & 165 & 311 & 121 \\
\hline$N=20$ & $\mathrm{~F}=70 \%$ & Mean $=32.4$ & Mean $=39.0$ & Median $=217$ & Median $=139$ & Median $=129$ & Median $=131$ & Median $=135$ \\
\hline
\end{tabular}

* "prolactin peak": maximum post-infusion prolactin value, as a percentage of the pre-infusion baseline prolactin level 'Step 1 results for this patient were reported in a previous publication.

\section{RESULTS}

Demographic characteristics of the patient subjects are presented in Table 1 . Both the patient and the healthy control groups included 14 women. The mean ages of the patient and control groups were $39.0 \pm 9.2$ (range: $20-55$ years) and $32.4 \pm 6.5$ (range: $23-50$ years), respectively.

\section{Test Results in Patients versus Healthy Control Subjects}

The patient group's baseline prolactin values did not differ significantly from those of the healthy control group at any of the steps, after controlling for age (all $p>3$ ). Covariate-adjusted baseline prolactin level means and pooled SDs $(\mathrm{ng} / \mathrm{ml})$ for patients vs. controls were: at Step 1, 6.6 vs. 7.0, $\mathrm{SD}=3.5$; at Step 2, 6.7 vs. $7.8, \mathrm{SD}=2.5$; at Step 3, 6.2 vs. $6.0, \mathrm{SD}=2.1$; and at Step $4,6.1$ vs. $6.4, \mathrm{SD}=2.2$.

The peak prolactin response to CMI challenge in the patient group was significantly blunted, relative to the matched healthy control subjects, prior to treatment (Step 1: $Z=2.5, p=.012$ ), and remained significantly blunted at each step (Step 2: $Z=3.0, p=.002$; Step 3: $Z=2.4, p=.016$; Step $4: Z=2.5, p=.012$ ) (see Figure 1 and Table 1). The median peak prolactin response for patients and their corresponding control subjects at each time point (expressed as percent of baseline) were: Step $1,139 \%$ vs. $217 \%$; Step 2, $129 \%$ vs. $219 \%$; Step 3, $131 \%$ vs. $251 \%$; and Step $4,135 \%$ vs. $232 \%$.

Log transformed AUCs of CMI plasma concentrations for the patient and control groups did not differ significantly at any of the four steps (all $p>$.1). Desmethylated CMI was not detected in any of the samples.

\section{Longitudinal CMI Test Results in Patients}

The patient group's baseline prolactin values at the initial, pre-treatment (Step 1) CMI challenge did not differ significantly from those at any of the subsequent challenges (all sign tests, $p>4$ ). Baseline prolactin level means ( \pm SDs) were: Step 1, $5.6 \pm 4.3 \mathrm{ng} / \mathrm{ml}$; Step 2, $5.4 \pm 3.8 \mathrm{ng} / \mathrm{ml}$; Step 3, $6.6 \pm 3.8 \mathrm{ng} / \mathrm{ml}$, and Step 4, $5.2 \pm 3.3 \mathrm{ng} / \mathrm{ml}$.

The peak prolactin responses to CMI challenge in patients at the initial, pre-treatment (Step 1) CMI challenge did not differ significantly from the peak responses to CMI challenge at any of the subsequent challenges (all sign tests, $p>.3$; see Figure 1 and Table 1) The median peak responses (expressed as percent of baseline) at each step were: 139\% (Step 1); 129\% (Step 2); $131 \%$ (Step 3); and 135\% (Step 4).

Paired $t$-test results indicated that the logged AUC of CMI plasma levels in the patient group did not differ significantly between Step 1 and any of the other three challenge steps (all $p>$.07). Desmethyl-CMI was not detected in any of the patient samples.

\section{DISCUSSION}

The most striking finding to emerge from this study was the persistent blunting in neuroendocrine respon- 


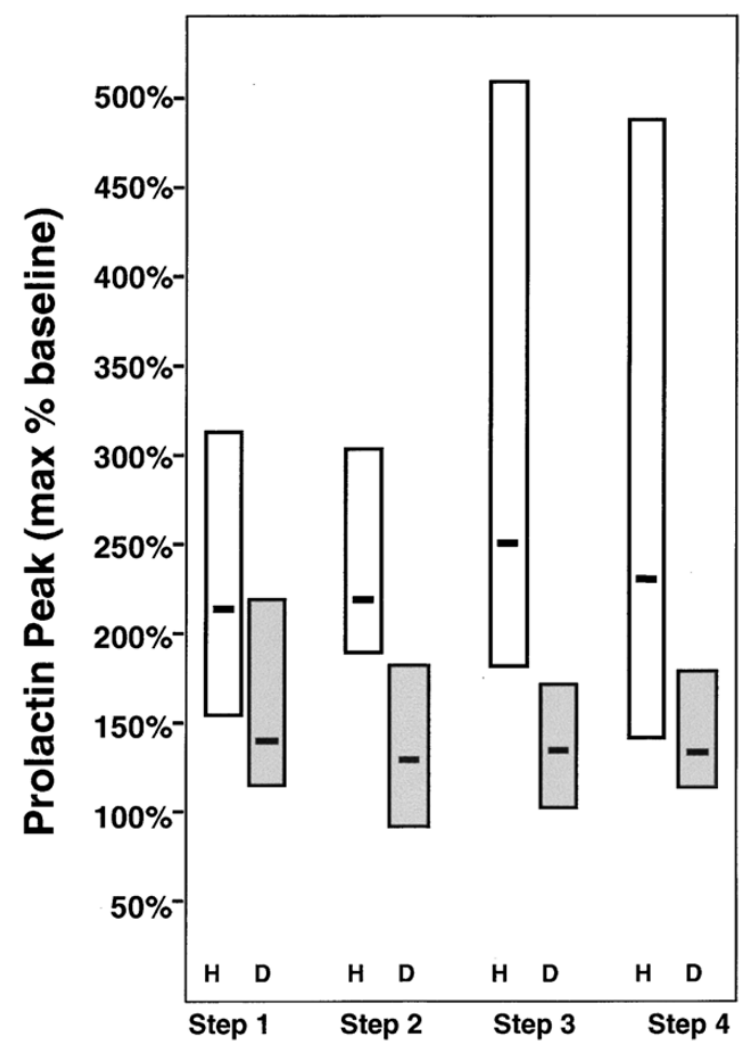

Figure 1. Longitudinal prolactin responses to CMI challenge in depressed patients (D) at four time points: baseline (step 1); following response to acute phase pharmacotherapy (step 2); at the end of continuation phase of treatment (step 3); and following medication wash-out after discontinuation of treatment (step 4). The prolactin responses for matched healthy control subjects $(\mathrm{H})$ for each available patient subject at a given time point are also presented (see text). The bars depict the median values, and the boxes enclose the $25^{\text {th }}$ to $75^{\text {th }}$ percentile values.

sivity to clomipramine challenge in depressed patients over time. In contrast to our original hypothesis, this measure of serotonergic function did not normalize after clinical response to antidepressant treatment. Instead, the prolactin response to clomipramine infusion remained virtually unchanged among the depressed patients, and different from values derived from healthy subjects, even when the depressed patients were studied in a medication-free, state of remission.

To our knowledge, this is the first study to examine serotonergic function in a cohort of depressed patients longitudinally, from baseline through the completion of the acute and continuation phases of treatment, and again after withdrawal from medication. There is support for these findings in other studies, which used different pharmacological challenge paradigms, and examined some, although not all, of the same specific phases of depressive illness. Several studies, for example, have reported abnormalities in neuroendocrine responses to 5-HT challenge in depressed patients who completed a course of pharmacotherapy. Kasper et al. (1990) applied d,l-fenfluramine challenges to depressed patients before and after "subchronic" treatment with diverse medications, including tricyclic and tetracyclic antidepressants, fluvoxamine, lithium, and alprazolam. Compared with pre-treatment challenge, post-treatment peak prolactin responses appeared to remain the same, and post-treatment peak prolactin changes from baseline were actually lower, reflecting a post-treatment increase in baseline prolactin values. More recently, Flory et al. (1998), also using d,l fenfluramine challenges, compared 29 patients with a history of at least one major depressive episode but currently in remission, to 58 matched controls with no histories of depression. Consistent with our findings, the formerly depressed patients, while in remission, demonstrated blunted prolactin response to d,l-fenfluramine challenge, compared with the control group. Meltzer et al. (1997) compared the cortisol and prolactin responses to 5-HTP challenge in 64 unmedicated depressed patients vs. 14 patients treated with tricyclic antidepressants and 16 patients treated with fluoxetine. Although the report does not describe the clinical outcome or clinical state of the treated subjects at the time of challenge, as in our study, there was no increase in neuroendocrine response to 5-HT challenge following tricyclic antidepressant treatment. In contrast, cortisol and prolactin responses were potentiated in the depressed patients who had received treatment with the SSRI fluoxetine.

Other reports have described findings that are not consistent with the above observations. O'Keane et al. (1992) applied d-fenfluramine challenges to 21 depressed patients before and after treatment with electroconvulsive therapy, fluoxetine, or amitriptyline. Although the cortisol responses remained blunted, the prolactin responses increased after treatment, regardless of outcome. Shapira's group has reported enhanced prolactin responses to d,l-fenfluramine challenge in 10 patients following treatment with imipramine (Shapira et al. 1989), and in 18 patients following bilateral ECT (Shapira et al. 1992). In addition, they studied eight remitted patients who had been withdrawn from medication for 14 days following six months of maintenance pharmacotherapy with either clomipramine and lithium, or lithium alone. The prolactin response to d,l-fenfluramine challenge in this group was not significantly different from the response following acute treatment with ECT or clomipramine, but was greater than the responses observed prior to treatment (Shapira et al. 1993). In an earlier report of a pilot study, our group observed an increase in prolactin response to CMI challenge in six patients who had responded to diverse antidepressant treatments, but not in seven patients who failed to respond (Leatherman et al. 1993). However, two of the six responders had mood disorders other than major depression (adjustment disorder with depressed mood; 
dysthymia), and the remaining four were receiving medications with direct biochemical effects on 5-HT neurotransmission (imipramine, fluoxetine, trazodone, and lithium) at the time of their rechallenge.

There are several potential explanations for the apparent inconsistencies across studies of neuroendocrine responsivity in depressed patients following antidepressant treatment. First, some studies examine the issue of trait vs. state abnormalities by comparing different groups of subjects (e.g., untreated vs. treated patients; patients in remission vs. healthy controls), while others, including this current report, follow a cohort of depressed patients longitudinally. Despite the practical complexities and difficulties in maintaining a longitudinal cohort, there are clear advantages to this approach. Since each subject serves as their own control, the confounding variables that may be imposed by inter-individual differences in 5-HT systems which are unrelated to depressive illness (e.g., age, gender) can be avoided.

Several of the above studies included subjects who were receiving treatment with diverse pharmacotherapies, including some with direct biochemical effects on 5-HT systems. When post-treatment challenge testing occurs in patients receiving medications with direct pharmacological effects on 5-HT systems (e.g., SSRIs, tertiary amine TCAs), changes from pre-treatment test results may be related to either clinical state (e.g., remission vs. persistent refractory illness) or the pharmacotherapy. In addition to these pharmacodynamic issues, there is the potential for pharmacokinetic interaction to complicate the interpretation of test results, due to a change in the metabolism of the challenge agent as a consequence of exposure to the treatment agent (Golden et al. 1991). For these reasons, we chose desipramine as our pharmacotherapy. Desipramine is a relatively specific norepinephrine reuptake inhibitor with minimal effects on the 5-HT transporter or any other 5-HT receptor family (Hyttel 1982). In healthy volunteers, it does not appear to increase the prolactin response to CMI challenge test in healthy volunteers (Golden et al. 1994a). In addition, it should not have any substantial impact on the pharmacokinetic aspects of our challenge, as confirmed by the CMI AUCs. In this way, we could be reasonably confident that the CMI challenge test results at the end of the acute and continuation phases of treatment reflected the state of 5-HT system responsivity in our subjects, rather than biological effects of their pharmacotherapy.

The application of different challenge agents may also contribute to the variance in observations across studies. None of the current available 5-HT challenge agents are ideal (van Praag et al. 1987), but each offers insight into components of the 5-HT system. Many of the studies have used d,l-fenfluramine. We have found that in healthy volunteers, d,l-fenfluramine evokes a more robust cortisol response, while CMI stimulates a stronger prolactin resonse (Nicholas et al. 1996), which probably reflects the different pharmacological properties of each agent interacting with the various pathways leading to the release of each of these neurohormones (Van de Kar et al. 1985). While several 5-HT challenge agents appear to be subject to seasonal effects (Brewerton et al. 1992; Grossman et al. 1996; Monteleone et al. 1999), this potential source of variation has not been observed with CMI challenge (Golden et al. 1996), which is clearly advantageous in studies which rechallenge individual subjects at various time points over the year.

Identification of the specific mechanism(s) involved in the blunted prolactin response to CMI challenge may shed insight into the pathophysiology of depression. In healthy volunteers, acute pharmacological blockade of the 5-HT3 receptor by ondansetron, or of the 5-HT1A receptor by pindolol, does not produce the neuroendocrine response pattern seen in depression (Golden et al. 1994b; Bebchuk et al. 1995). However, there are clear methodological limitations to this type of approach, and the precise mechanism of CMI induced prolactin release awaits further clarification.

Our findings suggest that altered neuroendocrine responsivity to CMI challenge in depression persists after recovery from acute illness. Thus, this measure of 5-HT dysregulation may represent an underlying biological vulnerability. Future studies should explore the potential genetic mechanisms which could account for this phenomenon, and thereby shed insight into the genetics of depressive illness itself.

\section{ACKNOWLEDGMENTS}

Preliminary results from this project were presented at the 150th Annual Meeting of the American Psychiatric Association, San Diego, May 21, 1997.

Supported in part by PHS grants MH-42145, MH-33127, MH19111, and RR-00046. Intravenous clomipramine (Anafranil ${ }^{\circledR}$ ) was provided by Ciba-Geigy. The contributions of the following individuals are gratefully acknowledged: Stanley Carson Pharm.D., Thomas P. Cooper, M.S., and George Mason, Ph.D.

\section{REFERENCES}

American Psychiatric Association (1987): Diagnostic and Statistical Manual of Mental Disorders, Third Edition-Revised. Washington DC, American Psychiatric Association

Anderson JM, Ware CJ, DaRoza Davis JM, Cowen PJ (1992): Decreased 5-HT-mediated prolactin release in major depression. Brit J Psychiatry 160:372-378

Bebchuk J, Nicholas LM, Durr AL, Ekstrom RD, Mason GA, Golden RN (1995): Clomipramine challenge test and 5-HT1A receptors. New Research Program and Abstracts, 148th Annual Meeting, American Psychiatric Association, pp 59

Brewerton TD, Mueller EA, Lesem MD, Brandt HA, Quearry B, 
George DT, Murphy DL, Jimerson DC (1992): Neuroendocrine responses to $\mathrm{m}$-chlorophenylpiperazine and l-tryptophan in bulimia. Arch Gen Psychiatry 49:852-861

Delgado PL, Charney DS, Price LH, Aghajanian GK, Landis H, Heninger GR (1990): Serotonin function and the mechanisms of antidepressant action. Reversal of antidepressant-induced remission by rapid depletion of plasma tryptophan. Arch Gen Psychiatry 47:411-418

Flory JC, Mann JJ, Manuck SB, Muldoon MF (1998): Recovery from major depression is not associated with normalization of serotonergic function. Biol Psychiatry 43: 320-326

Gilmore JH, Ruegg RG, Ekstrom RD, Knight B, Carson SW, Mason GA, Golden RN (1993): Altered prolactin response to clomipramine rechallenge in healthy volunteers. Biol Psychiatry 34:885-888

Golden RN, Ekstrom D, Brown TB, Ruegg R, Evans DL, Haggerty J Jr, Garbutt JC, Pedersen CA, Mason GA, Browne J, Carson SW (1992): Neuroendocrine effects of intravenous clomipramine in depressed patients and healthy subjects. Am J Psychiatry 149:1168-1175

Golden RN, Gilmore JH, Carson SW (1991): Antidepressant challenge tests: the interface of pharmacokinetics and pharmacodynamics. Psychopharmacol Bull 27:611-617

Golden RN, Gilmore JH, Ekstrom RD, Knight B, Ruegg RG, Miller HL, Carson SW (1996): The effects of age, gender, and season on serotonergic function in healthy subjects. Prog Neuro-Psychopharmacol Biol Psychiatry 20:13151323

Golden RN, Hsiao J, Lane E, Ekstrom RD, Rogers S, Hicks R, Potter WZ (1990a): Abnormal neuroendocrine responsivity to acute intravenous clomipramine challenge in depressed patients. Psychiatry Res 31:39-47

Golden RN, Hsiao J, Lane E, Rogers S, Hicks R, Potter WZ (1989): The effects of intravenous clomipramine on neurohormones in healthy subjects. J Clin Endo Metab 68:632-637

Golden RN, Leatherman M, Bebchuk J, Durr A, Carson S, Mason G (1994a): Effects of desipramine on 5-HT function in depressed patients and healthy subjects. Neuropsychopharmacol 10:269S

Golden RN, Leatherman M, Bebchuk J, Ekstrom RD, Durr A (1994b): The effects of 5-HT3 receptor blockade on the psychobiological response to clomipramine challenge. Neuropsychopharmacol 10:269S

Golden RN, Ruegg R, Brown T, Haggerty J Jr, Garbutt JC, Pedersen C, Evans DL (1990b): Abnormal neuroendocrine responsivity to clomipramine in depression. Psychopharmacol Bull 26:317-320

Grossman R, Cohen L, Rosen J, DeCaria C, Hollander E (1996): Seasonal effects in prolactin response to m-chlorophenylpiperazine challenge in obsessive-compulsive disorder. Biol Psychiatry 39:982-985

Hamilton M (1960): A rating scale for depression. J Neurol Neurosurg Psychiatry 23:56-62

Hyttel J (1982): Citalopram-pharmacologic profile of a specific serotonin uptake inhibitor with antidepressant activity. Prog Neuropsychopharmacol Biol Psychiatry 6:277-295

Kasper S, Vieria A, Schmidt R, Richter P (1990): Multiple hormone responses to stimulation with dl-fenfluramine in patients with major depression before and after antidepressive treatment. Pharmacopsychiatr 23:76-84

Laakmann G, Chuang I, Gugath M, Ortner M, Schmauss M, Wittman M (1983): Prolactin and antidepressants. In Tolis G (ed), Prolactin and Prolactinomas. New York, Raven Press, pp 151-161

Leatherman M, Ekstrom RD, Corrigan M, Carson SW, Mason GA, Golden RN (1993): Central serotonergic changes following antidepressant treatment: a neuroendocrine assessment. Psychopharmacol Bulletin 29:149-154

Maes M, Meltzer HY (1995): The serotonin hypothesis of major depression. In Bloom FE, Kupfer DJ (eds), Psychopharmacology: the Fourth Generation of Progress, $4^{\text {th }}$ ed. New York, Raven Press, pp 933-944

Meltzer H, Bastani B, Jayathillake K, Maes M (1997): Fluoxetine, but not tricyclic antidepressants, potentiates the 5-hydroxytryptophan-mediated increase in plasma cortisol and prolactin secretion in subjects with major depression or with obsessive-compulsive disorder. Neuropsychopharmacology 17:1-11

Monteleone P, LaRocca A, Fuschino A, Bortolotti F, Maj M (1999): Seasonal variation in plasma prolactin response to d-fenfluramine in healthy subjects. Psychoneuroendocrinology 24:201-208

Muscettola G, Wehr T, Goodwin F (1977): Effect of diet on urinary MHPG excretion in depressed patients and in normal controls. Amer J Psychiatry 134:914-916

Nicholas LM, Naftolowitz DF, Bebchuk JM, Heine AD, Ekstrom RD, Mason GA, Golden RN, Tancer ME (1996): Comparison of clomipramine and fenfluramine challenges. Biol Psychiatry 39:620

O'Keane V, McLoughlin D, Dinan TG (1992): D-fenfluramineinduced prolactin and cortisol release in major depression: response to treatment. J Affective Dis 26:143-150

Shapira B, Cohen J, Newman ME, Lerer B (1993): Prolactin response to fenfluramine and placebo challenge following maintenance pharmacotherapy withdrawal in remitted depressed patients. Biol Psychiatry 33:531-535

Shapira B, Lerer B, Kindler S, Lichtenberg P, Gropp C, Cooper T, Calev A (1992): Enhanced serotonergic responsivity following electroconvulsive therapy in patients with major depression. Br J Psychiatry 160:223-229

Shapira B, Reiss A, Kaiser N, Kindler S, Lerer B (1989): Effect of imipramine treatment on the prolactin response to fenfluramine and placebo challenge in depressed patients. J Affective Dis 16:1-4

Spitzer RL, Endicott J (1978): The Schedule for Affective Disorders and Schizophrenia. 3rd ed. New York, New York State Psychiatric Institute

Sutfin TA, D'Ambrosio R, Jasko WZ (1984): Liquid-chromatographic determination of eight tri- and tetracyclic antidepressants and their major active metabolites. Clin Chem 30:471-474

Van de Kar LD, Karteszi M, Bethea CL, Ganong WF (1985): Serotonergic stimulation of prolactin and corticosterone secretion is mediated by different pathways from the mediobasal hypothalamus. Neuroendocrinology 41:380384

van Praag HM, Lemus C, Kahn R (1987): Hormonal probes of central serotonergic activity: Do they really exist? Biol Psychiatry 22:86-98 